\title{
EVALUATION OF SINGLE IMPLANT ASSISTED MANDIBULAR OVERDENTURE IN DIABETIC PATIENTS
}

\author{
Ahmed M. Alam-Eldein* and Tamer M. Nasr Mostafa*
}

\begin{abstract}
Purpose: To evaluate single implant assisted mandibular overdenture in controlled type II diabetic patients after two years of function.

Materials and Methods: Thirty, completely edentulous patients with a mean age of fifty years old were included in this study. For each patient single implant $(3.5 * 13 \mathrm{~mm}$ Anyone Two- piece dental implant, Mega Gen Implant System, Korea) was placed at the anterior midline region with equator attachment to retain mandibular overdenture. Each patient was evaluated clinically concerning plaque index, probing depth and implant stability by using resonance frequency analysis and radiographically concerning marginal bone loss at baseline (overdenture insertion) and after 6, 12, 24 months after insertion. Data were collected and statistically analyzed using repeated measures ANOVA test.
\end{abstract}

Results: The cumulative implant success rate at two years was $100 \%$. There were no statistical significant differences along the time intervals $(\mathrm{P} \geq 0.05)$ regarding probing depth, implant stability and marginal bone loss.

Conclusions: Within the limitations of this study, single midline dental implant can be used successfully to assist mandibular overdenture in controlled type II diabetic edentulous patients.

KEYWORDS: Single implant, Implant overdenture, Type II diabetes.

\section{INTRODUCTION}

Tooth loss is one of the major handicaps in elderly patients, compromising their chewing efficiency and thus the nutritional status ${ }^{1}$. Rehabilitation using complete dentures on edentulous patients who suffer from a compromised alveolar bone often results in denture soreness, poor retention and instability, unclear pronunciation, and low chewing efficiency ${ }^{2,3}$.

Compared to the conventional complete denture, two or more implant-assisted mandibular overdentures can promote function and enhance success rates ${ }^{4-6}$. Although there are no reliable evidences on the ideal number of implants

* Lecturer, Prosthodontic Department, Faculty of Dentistry, Tanta University. 
for retention of a mandibular overdenture $^{7}$, the York consensus statement recommends at least two implants to support a mandibular overdenture(opposing complete maxillary dentures) for edentulous patients. However, economic constraints especially among the emerging elderly population in developing countries - make this treatment strategy financially challenging ${ }^{8,9}$.

In order to reduce the cost and treatment time, the concept of single implant-retained overdenture provides another option for elderly populations. The concept of a single median implant in an edentulous mandible was introduced by Cordioli in 1993 and the first 5-year results were published in 1997 with implant success rates of $100 \%{ }^{10,11}$.

An in vitro model study demonstrated that the single implant-supported overdenture increased retention and stability as compared with the conventional complete overdenture; furthermore, the biomechanical effects and patient satisfaction were comparable to those observed in a mandibular two-implant retained overdenture ${ }^{12}$.

Most studies reported a 100\% post-loading survival and there is no difference in the single implant survival compared to the 2-implant overdenture, when delayed loading was used ${ }^{13-15}$. A low number of early failures were observed for immediately or early loaded implants ${ }^{14,16}$.

Diabetes mellitus has long been considered a relative contraindication for implant procedures ${ }^{17}$. Well-controlled diabetic patients can be considered appropriate for implant therapy, while those lacking good glycemic control may be denied the benefits of implant therapy ${ }^{18}$. However; the potential benefits of implant therapy may be important for diabetic patients provided that their plasma glucose level is under metabolic control ${ }^{19}$.

Patients in good general health conditions are best candidates for implant therapy, however since single implant-assisted overdenture is a simplified and less invasive approach, it is a more feasible option for older and/or debilitated patients who have health restrictions or systemic conditions that increase the risk of extensive implant surgical procedures. If any systemic condition or disease is present, like diabetes or hypertension, it must be controlled and properly managed as part of the treatment planning and during the surgical interventions $\mathrm{s}^{20,21}$.

Although single implant-assisted overdentures are a promising alternative for compromised edentulous controlled diabetic patients, the limited research dedicated to this treatment concept has restricted its acceptance and implementation. The aim of this study was to evaluate single implant assisted mandibular overdenture in controlled type II diabetic patients after two years of function.

\section{MATERIALS AND METHODS}

This study was carried out on thirty completely edentulous, Type II diabetic patients with a mean age of 50 years old. Patient's general health was evaluated by taking full medical history. Laboratory investigations included the Glycosylated Hemoglobin Test (HbA1c Test) to ensure that all selected patients were controlled with levels ranging from $6.5 \%$ up to $7.0 \%$ and free from any other systemic diseases that might have an effect on implants osseointegration.

Patients whose HbAlc level was above 7\%, alcoholic, drug abuse, poor oral hygiene were excluded from this study.

Cone Beam CT was taken for all patients to show the height and width of bone as well as the bone density in the mandibular anterior midline area, and to check for any clinically undetectable pathology or bone abnormality. An informed consent approved by the ethics committee was signed by each patient after discussing the treatment plan with them and prior to initiation of treatment. 
An acrylic complete denture was fabricated for each patient with the conventional technique using semi-anatomic acrylic teeth set on semi-adjustable articulator. Mandibular acrylic dentures were duplicated using clear autopolymerized acrylic resin to produce surgical templates to aid in implant insertion in the anterior midline area. For each patient single implant $(3.5 * 13 \mathrm{~mm}$ Anyone Twopiece dental implant, Mega Gen Implant System, Korea) was placed at the anterior midline region using flapless technique.

Patients were allowed to use the new complete dentures for about 3 months to ensure proper adaptation. After about 3months; assessing the implant osseointegration by means of periapical film and intro-oral examination, patients were recalled, attaching abutments with implant fixtures after minimal surgical exposure of implant fixtures and each mandibular denture was relieved at the implant location, the plastic cap was placed on the implant abutment making sure that the denture was securely seated, the head of implant was then covered with a small shim to prevent excess acrylic resin from engaging any undercuts. The relieved area of the fitting surface of the mandibular denture was filled with autopolymerized acrylic resin, dentures were seated and patients were instructed to bite gently during setting of the acrylic resin. After the resin set, the dentures were removed, the plastic cap inside the mandibular denture was examined, and any excess resin was trimmed and inserted in the patient's mouth. Patients were then instructed on how to clean the denture and were asked to return on the following day to examine the denture bearing area and check for signs of tissue irritation (Fig, 1\& 2).

Patients were evaluated clinically and radiographically at baseline (overdenture insertion) and at 6, 12 and 24 months after overdenture insertion as follows:

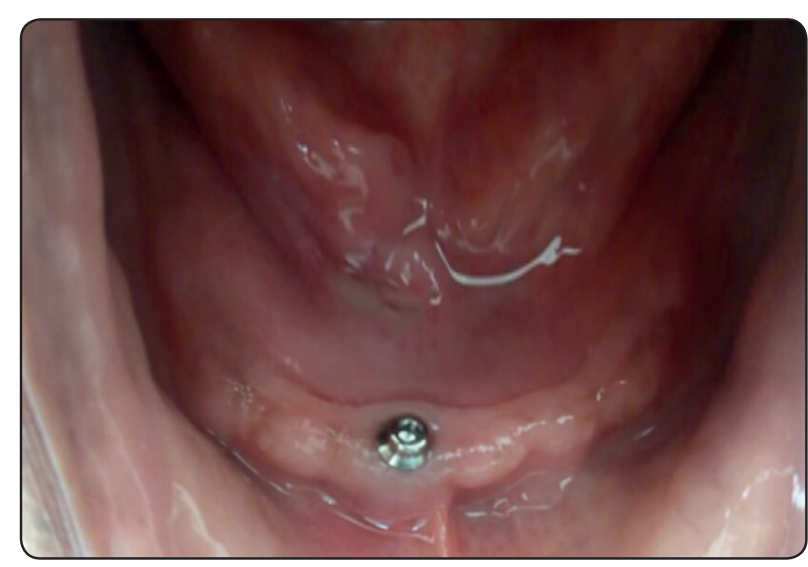

Fig. (1): Anterior midline single implant inserted in the mandibular edentulous arch.

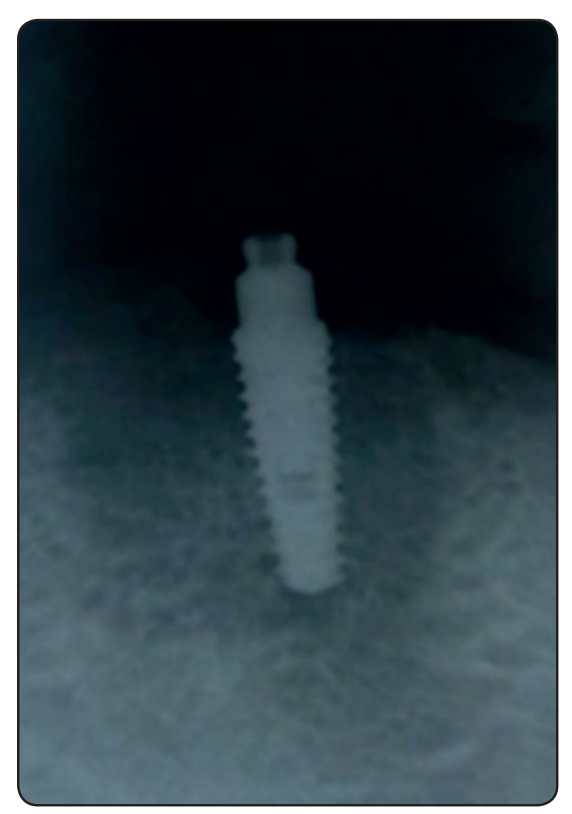

Fig. (2): A radiograph of the anterior midline single implant inserted in the mandibular edentulous arch.

\section{Plaque index:}

Plaque adherent to implant surfaces was quantified at four sites, buccal, lingual, mesial and distal, using a mouth mirror and a plastic dental explorer after air drying of the implant and gingiva. Each of the four areas was scored on a 4-point scale of 0-3 as described by Mombelli and Lang ${ }^{23}$ :

$0=$ No plaque is visible

$1=$ A film of plaque adhering to the free gingival margin and adjacent area of the implant, seen 
only after application of disclosing solution or by running the explorer across the implant surfaces.

$2=$ Moderate accumulation of soft deposits within the gingival pocket and on the gingival margin and/or adjacent to implant surface that can be seen by the naked eye.

3 = Abundance of soft matter within the gingival pocket and/or the gingival margin and adjacent implant surface.

The PI score was obtained by taking the average of the four plaque scores for the single implant.

\section{Probing depth ${ }^{24}$ :}

The probing depth was measured using a plastic periodontal probe (CPITN, R.O.R. international, Copenhagen, Denmark) around the implant surfaces in four areas (mid-buccal, mid-lingual, mid-mesial and mid-distal). The score was obtained by taking the average of the four scores for the single implant. Measurements of probing depth $\leq 1$ $\mathrm{mm}$ was recorded as $1 \mathrm{~mm}$, measurements exceeding $1 \mathrm{~mm}$, but less than $2 \mathrm{~mm}$ was recorded as $2 \mathrm{~mm}$, and so on.

2. Stability test by using OSSTELL ISQ (Implant stability quitent) (Osstell Mentor Göteborg, Sweden) ${ }^{25}$ :

- Smart peg was inserted inside the fixture and firmly screwed into it.

- The probe of Osstell was directed toward the smart peg without touching it ( $3 \mathrm{~mm}$ away from it) in two directions bucco- lingual and mesiodistal.

- The average of two readings was calculated

- Values less than 50 ISQ have a higher risk of failure. An increase in ISQ value during longterm examination implies that the implant became more stable ${ }^{26}$. Reports indicate that ISQ values are proportional to the extent of bone formation ${ }^{27}$.
- Reading above 50 ISQ indicate stable implants.

\section{Periapical radiographs ${ }^{28}$ :}

Periapical X-ray films were used to measure the marginal bone loss around the implants. The long cone paralleling technique using the Rinn XCP instrument (Rinn Co. Dentsply division, York, PA, USA) was used. It included the use of standardized periapical radiographs to detect changes in alveolar bone surrounding implant during the follow-up period. The standardized periapical radiographs were taken by the Xerograph Coping Process holder with a personalized bite registration record, made from putty rubber base impression material for extension cone $(35 \mathrm{~cm})$ paralleling technique. Every X-ray film was inserted into a slot in the bite-block. To ensure accurate repositioning of the film every time the radiograph was taken, the putty rubber base impression material (Express XT VPS, 3M ESPE AG, Germany) was folded around the bite-block, then a bite registration was obtained for X-ray film in closed mouth position, the putty bite-block with the occlusal registration was kept aside for the followup recall visits. Repeatable standardized periapical radiographs were made for implant to measure the mesial and distal bone heights. The measurements were made from the implant platform to the most coronal point of bone adjacent to the implant surface.

All radiographs were exposed using ultra speed periapical film (Kodak, Paris, France) with X-ray grid and $\mathrm{X}$ - ray unit set at $70 \mathrm{KV}$ and $10 \mathrm{~mA}$. With similar exposure times, the radiographs were developed under standardized condition using automatic process. The scanning settings were adjusted and noted down in order to be used each time with all the radiographs before each scan, 2600 DPI (dot per inch) high quality resolution, 100\% (1:1) scaling, fixed brightness and contrast setting, and no filter or other modifications were selected. The images were displayed on a 17 inches View sonic (3) col- 
ored monitor (1024 x 768 DPI). The digital image was then saved in an uncompressed format on the patient file. The stored images of each patient were then interpreted at the end of the follow-up period.

The marginal bone loss measurements were made from the reference point to the lowest observed point of contact of the marginal bone with the fixture. The reference point for the fixture was the fixture-abutment interface. The distance was measured to the nearest $0.01 \mathrm{~mm}$. These measurements were done using an analysis software program (Adobe Photoshop, Adobe Systems Incorporated, San Jose, CA, USA). The actual implant length served as a standard to calculate the bone height, calculations were made according to the following formula:

\section{$\mathrm{CBL}=\mathrm{IL} * \mathrm{BR} / \mathrm{MIL}$}

Where CBL is the calculated bone resorption, IL: Actual implant length, BR: measured bone resorption (mean mesial and distal) and MIL: measured implant length.

\section{Data analysis:}

All clinical and radiographic data were tabulated for each patient. Summary statistics (mean, standard deviation) were calculated and also tabulated; data were statistically analyzed using repeated-measures ANOVA test at 0.05 significance level.

\section{RESULTS}

Thirty patients were enrolled in this investigation. During the observation period, no implants were lost nor did fractures occur.

\section{Plaque Index:}

Figure (3) depicts the mean plaque index values at different periods of follow up and Table (1) lists the results of the repeated-measures ANOVA analysis for plaque index over time. On the initial examination after prosthesis insertion, mean \pm standard deviation of plaque index scores of all patients was $(1.44 \pm 0.25)$. During the followup period there was a statistical significant decrease of the plaque index $(P<0.001)$ where the mean for plaque index score decreased from those recorded at the previous observation periods to a value of $(0.66$ \pm 0.18 ) after 24 months of follow-up.

\section{Probing depth:}

Figure (4) shows the mean probing depth values at different periods of follow-up and Table (2) lists the results of the repeated-measures ANOVA analysis for probing depth over time.

TABLE (1): Results of the repeated-measures ANOVA for plaque index at different follow up periods.

\begin{tabular}{|c|c|c|c|c|c|c|c|c|c|}
\hline \multirow[b]{3}{*}{ T0 } & \multicolumn{2}{|c|}{ PI } & \multicolumn{7}{|c|}{ RANOVA } \\
\hline & \multirow{2}{*}{$\begin{array}{c}\text { Mean } \\
1.44\end{array}$} & \multirow{2}{*}{$\begin{array}{c}\text { SD } \\
0.25\end{array}$} & \multirow[t]{2}{*}{ F } & \multirow[t]{2}{*}{ P-value } & \multirow{2}{*}{ Time } & \multirow{2}{*}{$\begin{array}{c}\text { Mean } \\
\text { Difference }\end{array}$} & \multirow{2}{*}{$P$-value } & \multicolumn{2}{|c|}{$\begin{array}{l}\text { 95\% Confidence Interval } \\
\text { for Difference }\end{array}$} \\
\hline & & & & & & & & $\begin{array}{l}\text { Lower } \\
\text { Bound }\end{array}$ & Upper Bound \\
\hline T6 & 1.10 & 0.27 & \multirow[t]{3}{*}{94.731} & \multirow[t]{3}{*}{$<0.001 *$} & T0-T6 & 0.34 & $<0.001 *$ & 0.189 & 0.453 \\
\hline T12 & 0.86 & 0.27 & & & T0-T12 & 0.58 & $<0.001 *$ & 0.357 & 0.533 \\
\hline T24 & 0.66 & 0.18 & & & T0-T24 & 0.78 & $<0.001 *$ & 0.436 & 0.644 \\
\hline
\end{tabular}

*Significance: $P<0.05$

T0: At insertion. T6: after 6 months. T12: after 12 months. T24: After 24 months. 


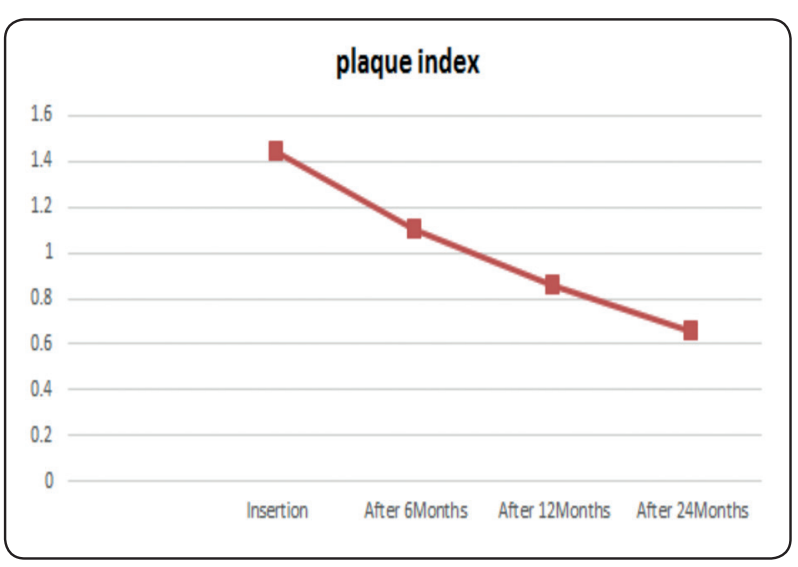

Fig. (3): Mean values of the plaque index at different periods of follow up.

After prosthesis insertion, mean \pm standard deviation for probing depth measurements of all patients was $(1.00 \pm 0.00)$. During the follow up period, there were no statistically significant differences of the probing depth $(P=0.178)$. The mean of probing depth measurements trended higher over time compared to those recorded at the previous observation periods and was $1.26 \pm 0.19($ mean \pm SD) at the end of the 24-month follow-up.

TABLE (2): Results of the repeated-measures ANOVA for probing depth at different follow up periods.

\begin{tabular}{|c|c|c|c|c|}
\hline & \multicolumn{2}{|c|}{ PD } & \multirow[b]{2}{*}{$\mathbf{F}$} & \multirow[b]{2}{*}{ P-value } \\
\hline & Mean & SD & & \\
\hline T0 & 1.00 & 0.00 & \multirow{4}{*}{1.657} & \multirow{4}{*}{0.178} \\
\hline T6 & 1.08 & 0.11 & & \\
\hline T12 & 1.17 & 0.16 & & \\
\hline T24 & 1.26 & 0.19 & & \\
\hline
\end{tabular}

*Significance: $P<0.05$

T0: At insertion. T6: after 6 months. T12: after 12 months. T24: After 24 months.

\section{Stability Test (Osstell ISQ):}

Figure (5) shows the mean of the stability test

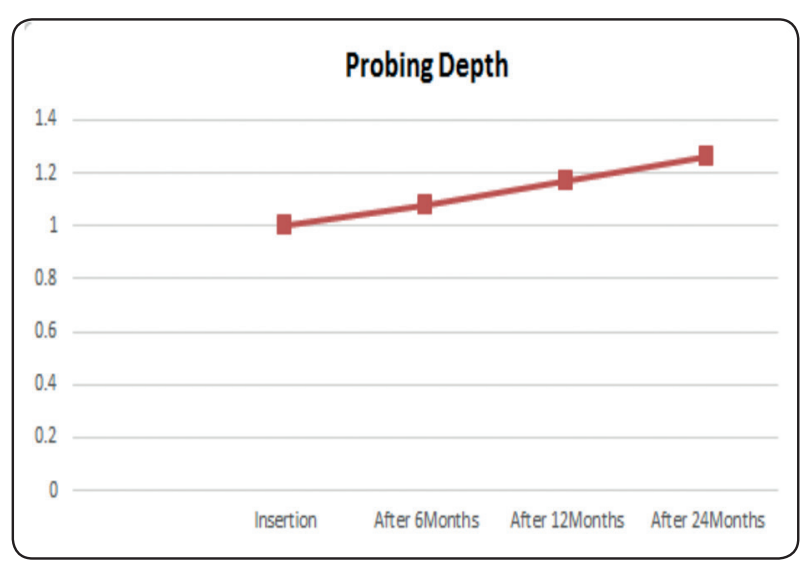

Fig. (4): Mean values of the probing depth at different periods of follow up.

scores (Osstell ISQ) at different periods of followup and Table (3) lists the results of the repeatedmeasures ANOVA analysis for the stability test scores (Osstell ISQ) over time. After prosthesis insertion, mean \pm standard deviation for the stability test scores (Osstell ISQ) of all patients was (70.73 \pm 2.78 ). During the follow up period, there were no statistically significant differences of the stability test scores (Osstell ISQ) $(P=0.166)$. The mean of the stability test scores (Osstell ISQ) increased by time compared to those recorded at the previous observation periods and was $73.63 \pm 2.74($ mean \pm SD) at the end of the 24-month follow-up.

TABLE (3): Results of the repeated-measures ANOVA for implant stability at different follow up periods.

\begin{tabular}{|c|c|c|c|c|}
\hline & \multicolumn{2}{|c|}{ ISQ } & \multicolumn{2}{|c|}{ RANOVA } \\
\hline & Mean & SD & $\mathbf{F}$ & P-value \\
\hline T0 & 70.73 & 2.78 & \multirow{4}{*}{1.734} & \multirow{4}{*}{0.166} \\
\hline T6 & 71.83 & 3.0 & & \\
\hline T12 & 72.0 & 2.75 & & \\
\hline T24 & 73.63 & 2.74 & & \\
\hline
\end{tabular}

*Significance: $P<0.05$

T0: At insertion. T6: after 6 months. T12: after 12 months. T24: After 24 months. 


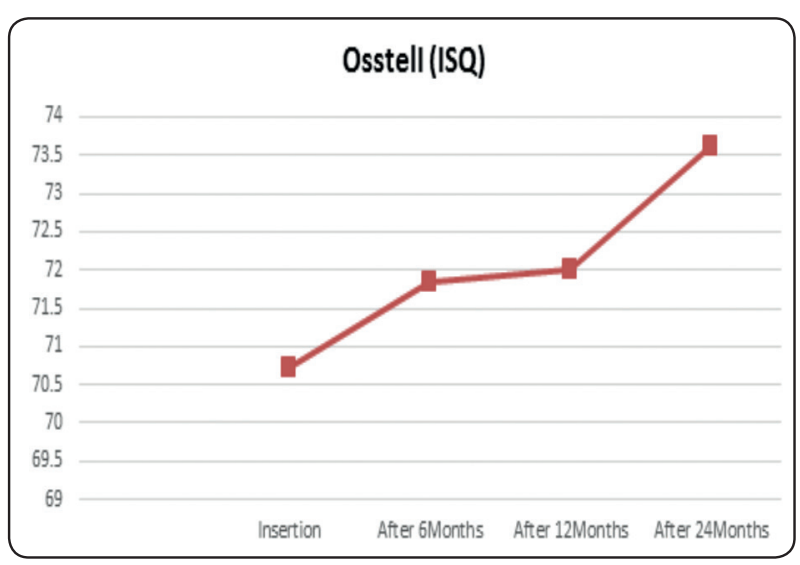

Fig. (5): Mean values of the stability test scores (Osstell ISQ) at different periods of follow up.

\section{Marginal bone loss:}

Figure (6) shows the mean of the marginal bone loss measurement values at different periods of follow-up and Table (4) lists the results of the repeated-measures ANOVA analysis for marginal bone loss over time. After prosthesis insertion, mean and standard deviation of marginal bone loss measurement of all patients was $(0.77 \pm$ $0.24)$. During the follow up period there were no statistically significant differences of the marginal bone loss $(P=0.308)$. The mean marginal bone loss reading trended higher over time compared to those recorded at the previous observation periods and was $1.25 \pm 0.42$ (mean \pm SD) after 24 months of follow-up.

TABLE (4): Results of the repeated-measures ANOVA for marginal bone loss at different follow up periods.

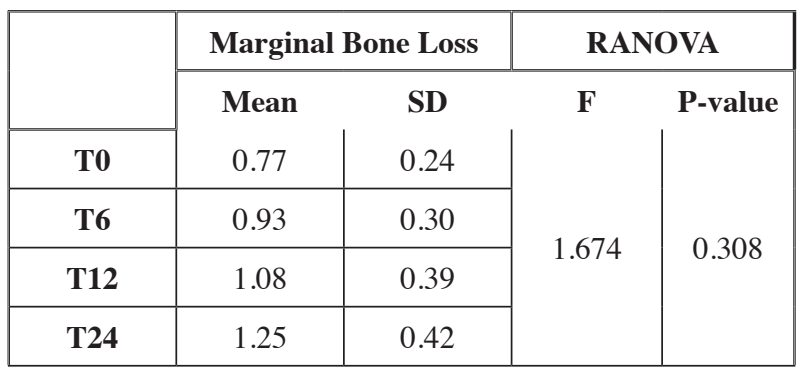

*Significance: $P<0.05$

T0: At insertion. T6: after 6 months. T12: after 12 months. T24: After 24 months.

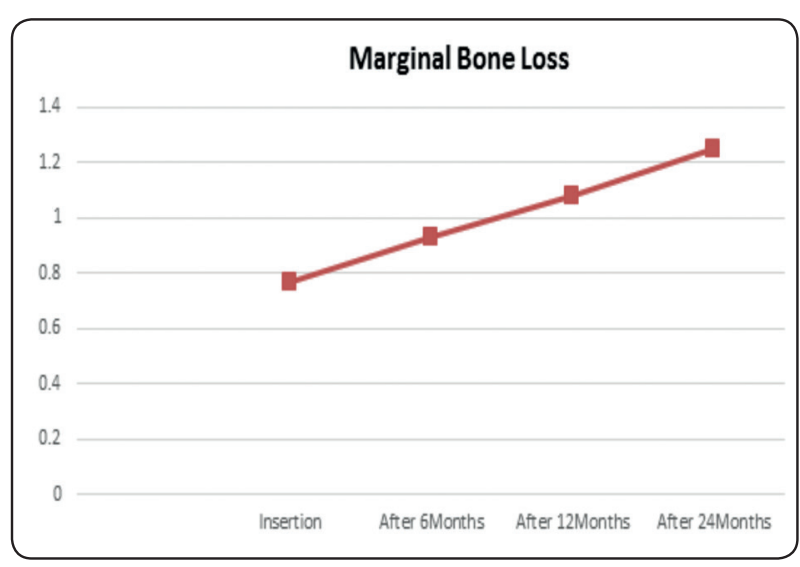

Fig. (6): Mean values of the marginal bone loss at different periods of follow up.

\section{DISCUSSION}

It has been widely accepted that two implants assisted mandibular overdentures should be recommended for edentulous patients, although single implant assisted overdentures also show practical and clinical potential.

Implants were placed in the anterior area of mandible. This region is the preferred site for single implant assisted overdenture for the following reasons: thicker cortical bone, lowered surgery risk by avoiding the inferior alveolar nerve and blood vessels, and, finally, a larger tissue-supporting area to prevent overloading on implant. Although there was some concern regarding the potential risk of mandibular fracture because of the anatomical structure $^{29}$, there was little difference found between the risk anticipated in overdentures assisted by one implant and those assisted by two implants ${ }^{30}$.

A 3D finite element analysis done by Liu et al. in 2013 showed that single implant assisted mandibular overdenture does not show any damaging strain concentration in the bone around an implant because when vertical load is applied on the implant overdenture, it rotated side to side but under same loading conditions. Two-implant assisted mandibular overdenture showed more apparent 
rotations around the fulcrum line passing through the two implants and the maximum equivalent stress in the abutments was higher in the other models ${ }^{31}$.

In this study, a significant decrease in plaque index was observed over two years of follow-up and may be attributed to routine hygienic recall visits and to the patients' efforts in maintaining a high level of oral hygiene. This matches the results from previous studies which reported successfully osseointegrated implants in patients who followed regular oral hygiene instructions $\mathrm{s}^{32,33}$. This may explain the results form Ferreira et $\mathrm{al}^{34}$ where implants in diabetic patients with good glycemic control were found not to be associated with an increased risk of peri-implantitis when compared with non diabetic subjects.

It was also observed a slight trend of increasing probing depth around the implants during the followup periods, although it did not reach statistical significance. These findings could be attributed to bone resorption during the first year after implant placement; the increases were within acceptable values and are in agreement with previously reported results of a probing depth increase after one year follow-up period and explanation that this phenomenon of up to $1 \mathrm{~mm}$ marginal bone loss is related to maturation of bone after implant placement and adaptation of bone to withstand functional forces ${ }^{35}$. The results this study are also in agreement with the work from Turkyilmaz ${ }^{36}$ who reported no pathological probing depth changes in patients with well-controlled Type II diabetic patients through one year follow-up period, and no evidence of diminished clinical success or significant complication related to implant treatment was found for this patient population.

Slight increasing of marginal bone loss around the implants was observed during the follow-up periods. Although statistically insignificant, these changes match the results of multiple clinical trials concluding that single median implant can retain a mandibular over denture well for up to 5 years without the implant failing, when delayed loading was used $^{13-15}$. These results provide further support to Chrcanovic et al ${ }^{37}$ conclusion that the difference between the insertion of dental implants in nondiabetic and diabetic patients did not statistically affect the implant failure rates, provided that they present with moderate $\mathrm{HbA1c}$ values indicative of good glycemic control. The amount of bone level changes in this study was within the criteria for implant success suggested by Albrektsson and coworkers $^{38}$.

In this study, the use of flapless implant surgery might be a reason of the success rate of the implants. The flapless implant surgery "minimally invasive" preserves maximum amount of blood supply to the bone resulting in decreasing the amount of the marginal bone loss around the implants ${ }^{39}$.

Implant stability is a critical factor that determines the long-term success of dental implants ${ }^{40}$. In this study, all the Osstell ISQ values are more than 70 and this indicates successful Osseointegration ${ }^{41}$. An ISQ range of 70-74 could, therefore, represent a state of stability for implants in the midline of the mandible assisted mandibular single-implant overdentures. This matches the results from previous studies which reported improved stability for implants in the midline of the mandible $\mathrm{e}^{42-45}$.

Due to the limitations of this study, the authors suggest that the small sample size may have affected the power to show a statistical significant change in probing depth, marginal bone loss and implant stability. Also longer evaluation period may be needed to asses success of single anterior median implant assisted over denture in type II diabetic patients.

\section{CONCLUSION}

Within the limitations of this study concerning evaluation period and sample size, single anterior median implant can assist a mandibular over denture well for up to two years without the implant failing, 
when delayed loading was used in controlled type II diabetic edentulous patients.

\section{Conflict of interest:}

The Authors declare that they have no conflict of interest, have full control of all primary data.

\section{REFERENCES}

1. Koole SH, De Bruyn. Contemporary undergraduate implant dentistry education: a systematic review. Eur J Dent Edu. 2014;18:11.

2. Heckmann SM, Heussinger S, Linke JJ, Graef F, Proschel P. Improvement and long-term stability of neuromuscular adaptation in implant-supported overdentures. Clin Oral Implants Res. 2009;20:1200.

3. Ueda T, Kremer U, Katsoulis J, Mericske-Stern R. Longterm results of mandibular implants supporting an overdenture: Implant survival, failures, and crestal bone level changes. Int J Oral Maxillofac Implants. 2011;26:365.

4. Bergendal T, Engquist B. Implant-supported overdentures: a longitudinal prospective study. Int J Oral Maxillofac Implants. 1998; 13:253.

5. Donatsky O. Osseointegrated dental implants with ball attachments supporting overdentures in patients with mandibular alveolar ridge atrophy. Int J Oral Maxillofac Implants. 1993;8:162.

6. Gotfredsen K, Holm B. Implant-supported mandibular overdentures retained with ball or bar attachments: a randomized prospective five year study. Int J Prosthodont. 2000; $13: 125$.

7. Klemetti E. Is there a certain number of implants needed to retain an overdenture? J Oral Rehabil. 2008;35:80.

8. Owen PC.Appropriatech: prosthodontics for the many, not just for the few. Int J Prosthodont. 2004;17:261.

9. Carlsson GE, Omar R. The future of complete dentures in oral rehabilitation. A critical review. J Oral Rehabil. 2010;37:143.

10. Cordioli GP: Mandibular overdentures supported by a single implant. Minerva Stomatol. 1993,42:469.

11. Cordioli G, Majzoub Z, Castagna S. Mandibular overdentures anchored to single implants: a five year prospective study. J Prosthet Dent. 1997;78:159.
12. Srinivasan M, Makarov NA, Herrmann FR, Muller F. Implant survival in 1- versus 2-implant mandibular overdentures: a systematic review and meta-analysis. Clin Oral Implants Res. 2014;28.

13. Liddelow GJ, Henry PJ. A prospective study of immediately loaded single implant-retained mandibular overdentures: preliminary one-year results. J Prosthet Dent. 2007;97:126.

14. Alsabeeha NH, Payne AG, de Silva RK, Thomson WM. Mandibular single-implant overdentures: preliminary results of a randomised-control trial on early loading with different implant diameters and attachment systems. Clin Oral Implants Res. 2011;22:330.

15. Hyland R, Ellis J, Thomason M, El-Feky A, Moynihan P. A qualitative study on patient perspectives of how conventional and implant-supported dentures affect eating. J Dent. 2009;37:18.

16. Kronstrom M, Davis B, Loney R, Gerrow J, Hollender L. A prospective randomized study on the immediate loading of mandibular overdentures supported by one or two implants; a 3 year follow-up report. Clin Implant Dent Relat Res. 2014;16:323.

17. Kayal RA, Tsatsas D, Bauer MA, Allen B, Al-Sebaei MO, Kakar S, et al. Diminished bone formation during diabetic fracture healing is related to the premature resorption of cartilage associated with increased osteoclast activity. J Bone Miner Res. 2007;22:560.

18. Oates TW, Huynh-Ba G, Vargas A, Alexander P, Feine J. A critical review of diabetes, glycemic control, and dental implant therapy. Clin Oral Impl Res. 2013;24:117.

19. Qates T, Galloway P, Alexander P, Green A, Huynh-Ba G, Feine J, McMahan C. The effects of elevated hemoglobin A1c in patients with type 2 diabetes mellitus on dental implants. J Am Dent Assoc. 2014;145:1218.

20. Dubey RK, Gupta DK, Singh AK. Dental implant survival in diabetic patients; review and recommendations. Natl J Maxillofac Surg. 2013;4(2):142.

21. Cheng T, Ma L, Ling XL, Sun GF, Ji XH, Huo JY, Wang NY. Use of a single implant to retain mandibular overdenture: A preliminary clinical trial of 13 cases. J Dent Sci. 2012;7:261.

22. Standards of medical care in diabetes. Diabetes Care. 2010;33(Suppl):11.

23. Mombelli A, Lang N. Clinical parameters for the evaluation of dental implants. Periodontol 2000. 1994;4:81. 
24. Akagawa Y, Matsomoto T, Hashimoto M, Tsuru H. Clinical evaluation of the gingival around single crystal sapphire endosseous implant after experimental ligature induced plaque accumulation in monkeys. J Prosthet Dent. 1992; 68:111.

25. Huang HM, Chiu CL, Yeh CY, Lin CT, Lin LH, Lee SY. Early detection of implant healing process using resonance frequency analysis. Clin Oral Implants Res. 2003;14:437.

26. Capek L, Simunek A, Slezak R, Dzan L. Influence of the orientation of the Osstell@ transducer during measurement of dental implant stability using resonance frequency analysis: A numerical approach. Med Eng Phys. 2009; 31:764.

27. Mihoko A, Sang-Hoon P, Hom-Lay W. Methods used to assess implant stability status. Int J Oral Maxillofac Implants. 2007;22:743.

28. Walters RA. Vertical alveolar bone changes related to overdenture abutment teeth. J Prosthet Dent. 1987;57:309.

29. Schneider GB, Synan WJ. Use of a single implant to retain a mandibular complete overdenture on the compromised atrophic alveolar ridge: a case report. Spec Care Dentist. 2011;31:138

30. Gonda T, Maeda Y, Walton JN, MacEntee MI. Fracture incidence in mandibular overdentures retained by one or two implants. J Prosthet Dent. 2010;103:178.

31. Liu J, Pan S, Dong J, Mo Z, Fan Y, Feng H. Influence of implant number on the biomechanical behaviour of mandibular implant-retained/supported overdentures: a threedimensional finite element analysis. J Dent. 2013;41:241.

32. Leonhardt A, Dahlen G, Renvert S. Five-year clinical, microbiological, and radiographical outcome following treatment of peri-implantitis in man. J Periodontol. 2003;74:1415.

33. Mostafa TM, El-Sheikh MM, Abd El-Fattah F. Implantconnected versus tooth-connected implant-supported partial dentures: 2-year clinical and radiographic comparative evaluation. Int $\mathrm{J}$ Periodont Rest Dent. 2015;35:335.

34. Ferreira S, Silva G, Cortelli J, et al. Prevalence and risk variables for peri implant disease in Brazilian subjects. J clin periodontol. 2006;33:929.
35. Visser A, Gerr M, Henny J, et al. Mandibular overdentures supported by two or four endosseous implants: A 5-years prospective study. Clin Oral Imp Res. 2005;16:19.

36. Turkyilmaz I. One-year clinical outcome of dental implants placed in patients with type 2 diabetes mellitus: a case series. Imp Dent. 2010;19:323.

37. Chrcanovic BR, Albrektsson T, Wennerberg A. Diabetes and Oral Implant Failure: A Systematic Review. J Dent Res. 2014;93:859.

38. Albrektsson T, Zarb G, Worthington P, Eriksson A. The long-term efficacy of currently used dental implants: A review and proposed criteria of success. Int J Oral Maxillofac Implants. 1986;1:11.

39. Al-Juboori MJ, Bin Abdulrahaman S, Jassan A. Comparison of flapless and conventional flap and the effect on crestal bone resorption during a 12-week healing period. Dent Implantol Update. 2012;23:9.

40. Rabel A, Kohler SG, Schmidt-Westhausen AM. Clinical study on the primary stability of two dental implant systems with resonance frequency analysis. Clin Oral Investig. 2007;11:257.

41. Sjostro“m M, Lundgren S, Nilson H, Sennerby L. Monitoring of implant stability in grafted bone using resonance frequency analysis. A clinical study from implant placement to 6 months of loading Int J Oral Maxillofac Surgery. 2005;34:45.

42. Roos J, Sennerby L, Lekholm U, Jemt T, Grondahl K, Albrektsson T. A qualitative and quantitative method for evaluating implant success: a 5-year retrospective analysis of the $\mathrm{Bra}^{\circ}$ nemark implant. Int J Oral Maxillofac Implants. 1997;12:504.

43. Albrektsson T, Zarb GA. Determinants of correct clinical reporting. Int J Prosthodont. 1998;11:517.

44. Liddelow GJ, Henry PJ. A prospective study of immediately loaded single implant-retained mandibular overdentures: preliminary one-year results. J Prosthet Dent. 2007;97:126.

45. Liddelow GJ, Henry PJ. The immediately loaded single implant-retained mandibular overdenture: a 36-month prospective study. Int J Prosthodont. 2010;23:13. 